\title{
The Development of a Warm-Weather Relative Stress Index for Environmental Applications
}

\author{
Jill D. WatTS And Laurence S. Kalkstein \\ University of Delaware, Newark, Delaware
}

(Manuscript received 23 May 2003, in final form 1 October 2003)

\begin{abstract}
The heat stress index (HSI) is a new, comprehensive summer index that evaluates daily relative stress for locations throughout the United States based on deviations from the norm. The index is based on apparent temperature and other derived meteorological variables, including cloud cover, cooling degree-days, and consecutive days of extreme heat. Statistical distributions of meteorological variables are derived for 10-day periods of the annual cycle so that percentile values for each parameter can be determined. The daily percentile values for each variable are then summed, and a statistical distribution is fit to the summed frequencies. The daily HSI value is the percentile associated with the location of the daily summed value under the summation curve. The index is analyzed and spatially verified by comparing intra- and interregional results. Although stations from various climate regions have different criteria defining an excessive heat stress event, neighboring stations typically produce similar HSI results because they are usually affected by the same air mass. To test the effectiveness of the HSI, a relationship between the index results and mortality values is made. Overall, the highest mortality days are associated with the highest HSI values, but high-HSI days are not always associated with high numbers of deaths. A mortality study such as this one is just one of many potential environmental applications of the HSI. Other applications include implementing the index to correlate extreme weather conditions with resource consumption, such as electric-utility load, to determine conditions for which load levels are excessive. The ability to forecast the HSI using a variety of weather forecasting tools has also generated interest within various industries that have a need to issue weather stress advisories, watches, and warnings.
\end{abstract}

\section{Introduction}

Researchers have long recognized that the level of human physical comfort is not only dependent upon air temperatures, but is related to the interaction of a number of weather variables. For example, human response to a moist, hot summer day varies considerably from the response to dry heat. In addition, that same hot, dry day elicits a different reaction from people in Philadelphia, Pennsylvania, and Phoenix, Arizona.

In an effort to quantify the reaction differences among such days, numerous indices have been developed over the years that give a measure of how comfortable a person feels based on the current weather conditions (Hevener 1959; Thom 1959; Masterton and Richardson 1979; Steadman 1984; Höppe 1999; Jendritzky et al. 2001). The National Weather Service (NWS) heat index is an approximation of the Steadman (1979a,b, 1984) apparent temperature (AT) tables (NWS 1992). The main shortcoming of the NWS heat index is that its formulation does not incorporate a number of variables

Corresponding author address: Jill D. Watts, Center for Climatic Research, Department of Geography, 216 Pearson Hall, University of Delaware, Newark, DE 19716.

E-mail: jdwatts@udel.edu that contribute to weather stress, including wind speed, cloud cover, and solar radiation, which are obvious factors contributing to "how hot it feels" on a given day. In addition, none of the previously developed indices account for the cumulative negative impact of heat over a period of, for example, several days.

Virtually all comfort indices are derived solely on absolute conditions and do not consider relative stress and adaptation based on time and location. For example, many NWS offices issue heat stress alerts based on an absolute condition of a predicted NWS heat index value of $40.6^{\circ} \mathrm{C}$ or greater and a minimum air temperature of $26.7^{\circ} \mathrm{C}$ or higher for two consecutive days. Although the NWS is now recognizing the shortcomings involved in this delineation, these thresholds were arbitrarily determined and have been sustained historically. The current thresholds have little relation to human weather response, time of year, or the climatological makeup of the locale.

Kalkstein and Davis (1989) established threshold temperatures, which represent the temperature beyond which human mortality significantly increases, for cities throughout the United States. The results show that threshold temperatures vary widely across the country, from the upper $20 \mathrm{~s}\left({ }^{\circ} \mathrm{C}\right)$ in New England to over $38^{\circ} \mathrm{C}$ 
in the southern United States. This variation explains why there can be significant excess mortality in New York City, New York, when apparent temperatures exceed $32^{\circ} \mathrm{C}$, but not a similar response in Dallas, Texas, where these conditions are common during the summer. These results clearly identify the need for a comprehensive relative index.

Kalkstein and Valimont $(1986,1987)$ introduced the only commonly known relative index, the weather stress index (WSI). This index is calculated by evaluating how AT varies from a mean value for a given hour on each day at each locale. However, the WSI excludes other important meteorological parameters related to heat stress. Although used in research (Balling and Brazel 1986), the WSI was never officially adopted by the NWS or widely used by climate scientists.

A new, comprehensive summer relative comfort index, the heat stress index (HSI), is introduced in this paper. This index improves upon the limitations of the current widely used indices in the United States, as well as the shortcomings of the WSI, and can be useful in research and operational applications. The HSI has the ability to evaluate daily mean relative stress values for each first-order weather station in the United States. It includes important variables not used in previous indices, such as consideration of the impact of consecutive days of stressful weather, daily cloud cover (as a surrogate for solar load), and accumulation of heat through the day. In addition, the index has been designed to fit seamlessly into NWS forecasts, permitting daily values to be calculated for time periods up to $48 \mathrm{~h}$ in advance.

\section{Index development}

\section{a. Meteorological data}

The U.S. Surface Airways and Airways Solar Radiation hourly weather data (known as TD-3280) were acquired from the National Climatic Data Center for every active first-order weather station with data corresponding to the current 30-yr climate normals (19712000) (National Climatic Data Center 2003). Over 230 first-order weather stations across the continental United States met these criteria (Fig. 1).

For each of these stations, hourly air temperature $\left({ }^{\circ} \mathrm{C}\right)$, dewpoint temperature $\left({ }^{\circ} \mathrm{C}\right)$, relative humidity $(\%)$, cloud cover (tenths), and wind speed $\left(\mathrm{m} \mathrm{s}^{-1}\right)$ data were extracted for the warm-season months (May-September). An entire day was omitted if any hourly observations within that day were missing, because the index is based on daily averages and extremes.

\section{b. Method}

A unique algorithm for calculating the HSI was developed for each 10-day period from May through September (1-10, 11-20, 21-31 May, etc.) at each location. The steps necessary to create each HSI algorithm are summarized in a flow chart (Fig. 2).

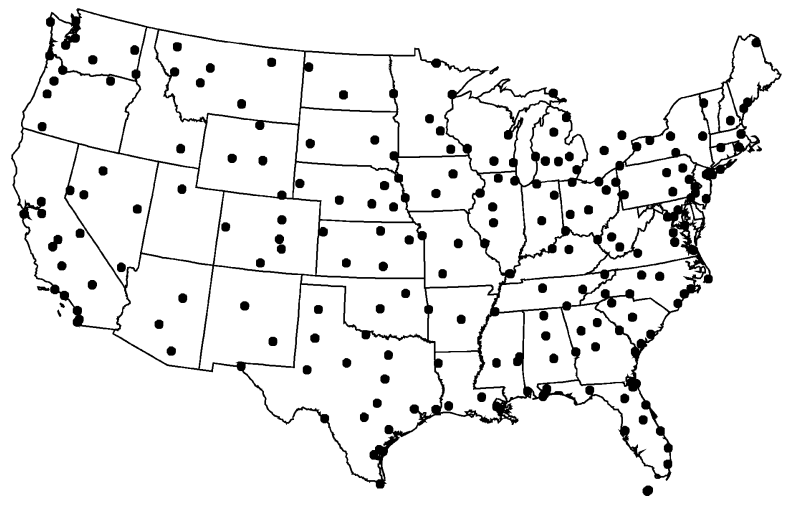

FIG. 1. Spatial distribution of first-order weather stations throughout the continental United States that existed from 1971 to 2000.

A 10-day interval is chosen to minimize the variability of mean weather conditions over the period of time to which a single algorithm is applied. A monthly time scale was originally considered, but too much variability occurs from the beginning to the end of the month, most notably early and late in the warm season. For example, the conditions in early June and late August tended to lower the average of the entire month, skewing the overall results. A future improvement is to develop even shorter, possibly daily, intervals to eliminate any temporal variability in mean meteorological conditions altogether. However, it is uncertain whether the slight increase in accuracy would compensate for the much greater effort necessary to accomplish this task. It is possible that, for certain precise applications, such as utility load estimation, this increase in accuracy might provide a benefit. Regardless, the basic method would remain the same, and the goal of this paper is to introduce the methods behind the HSI.

The first step is to calculate hourly apparent temperature values using the Steadman (1984) "in the shade" algorithm. The Steadman AT index is based on the physiological, clothing, and heat transfer effects on humans. Apparent temperature in the shade accounts for outdoor conditions in which the effects of wind are felt but the effects from extra radiation are not considered.

The second step is to select and to calculate the five parameters necessary to calculate the HSI. These parameters consist of daily maximum and minimum Steadman AT values (ATMAX and ATMIN), cooling degreedays (CDD), mean cloud cover (CCMEAN), and the number of consecutive days of extreme heat (CONS). These variables were selected based on our previous knowledge of human and social responses to extreme weather conditions. Although more can be included, these variables are deemed best because they encompass the most important factors relating to societal response: thermal conditions during daytime and nighttime, calculation of accumulated daily heat load, solar load, and the temporal extent of extreme heat. A description of each variable follows. 


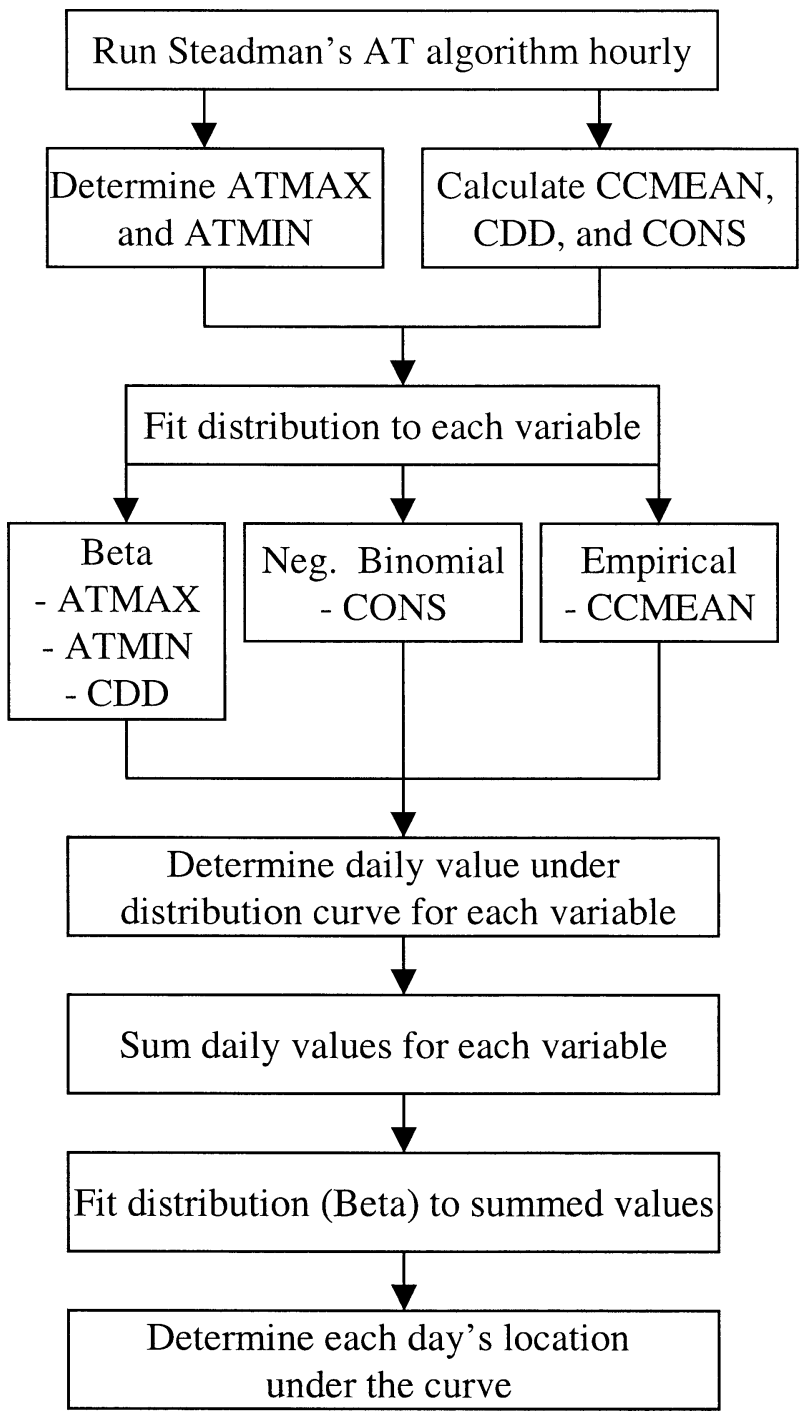

FIG. 2. Steps involved in the development of the heat stress index. Maximum and minimum apparent temperature (ATMAX and ATMIN), mean cloud cover (CCMEAN), cooling degree-days (CDD), and a consecutive day count (CONS) are the variables used to create the index.

1) $\operatorname{ATMAX}(\mathrm{ATMIN})$ is the highest (lowest) hourly AT value recorded over a 24 -h period. ATMIN affects human stress levels as much as or more than ATMAX does because high daily ATMINs hinder overnight heat relief. For example, elevated ATMIN, along with high ATMAX, conditions during the 1995 Chicago, Illinois, heat wave rendered that event particularly unusual and deadly (Karl and Knight 1997).

2) The CDD variable is calculated by summing the number of degrees above an hourly apparent temperature of $18.3^{\circ} \mathrm{C}$ over a $24-\mathrm{h}$ period. CDD accounts for temperature fluctuations such as those often associated with a temperature drop after the onset of a thunderstorm or passage of a cold front, which can bring relief to an otherwise stressful situation. It is frequently the case that higher CDD totals occur on days with lower ATMAX but no cooling thunderstorm activity; the former day is considered to be more stressful to humans than the latter (Kalkstein et al. 1996).

3) CCMEAN represents the average hourly cloud cover values from 1000 to 1800 LST. These hours were chosen because clear skies during the daytime generally add stress through an increased solar load (Kilbourne 1997). The CCMEAN scale is 0.0-8.0, and the mean cloud cover values are smoothed such that if $0.00 \leq$ CCMEAN $<0.25$ then CCMEAN $=0.0$, if $0.25 \leq$ CCMEAN $<0.75$ then CCMEAN $=0.5$, if $0.75 \leq$ CCMEAN $<1.25$ then CCMEAN $=1.0$, if $1.25 \leq$ CCMEAN $<1.75$ then CCMEAN $=1.5$, and so on, up to 8.0. It is important to note the possible misinterpretation of cloud cover data resulting from the gradual implementation of automated surface observing system (ASOS) stations in the United States during the early 1990s. ASOS stations only report ceiling up to $12000 \mathrm{ft}$ and do not distinguish between thin and opaque cloud cover. Although some ASOS sites are augmented by human observers who can help to overcome this shortcoming, many ASOS sites are not (National Climatic Data Center 2003).

4) A consecutive day (CONS) is counted when the ATMAX value was at least one standard deviation above the AT mean over the 10-day period. The criteria were arbitrarily chosen but produced logical results such that consecutive days were a rarity, especially in locales with less climate variability. The count increases with each consecutive day that ATMAX exceeds the threshold but drops back to zero when conditions are not met or the day's data are missing. Consecutive day count is included because there is a negative human health impact of extreme weather that increases with each day of persisting stressful conditions (Kalkstein and Davis 1989; Kilbourne 1997).

The third step involves fitting a statistical distribution to each of the variable frequencies. Variable frequency patterns for every 10-day interval and station were considered, and a distribution was chosen that was deemed the best overall fit. ATMAX, ATMIN, and CDD frequencies are approximated by beta distributions. A negative binomial distribution is fit to the CONS frequencies, because it captures best the overwhelming number of zero consecutive days that are consistently present at every location during each period. An empirical fit is the best option for the CCMEAN frequencies because the patterns vary greatly among stations. An empirical fit means that the curve is fit directly by connecting a line to each frequency value associated with observations rather than by approximating or smoothing the data (Figs. 3a-e, 4a-e).

The fourth step is the determination of the percentile 

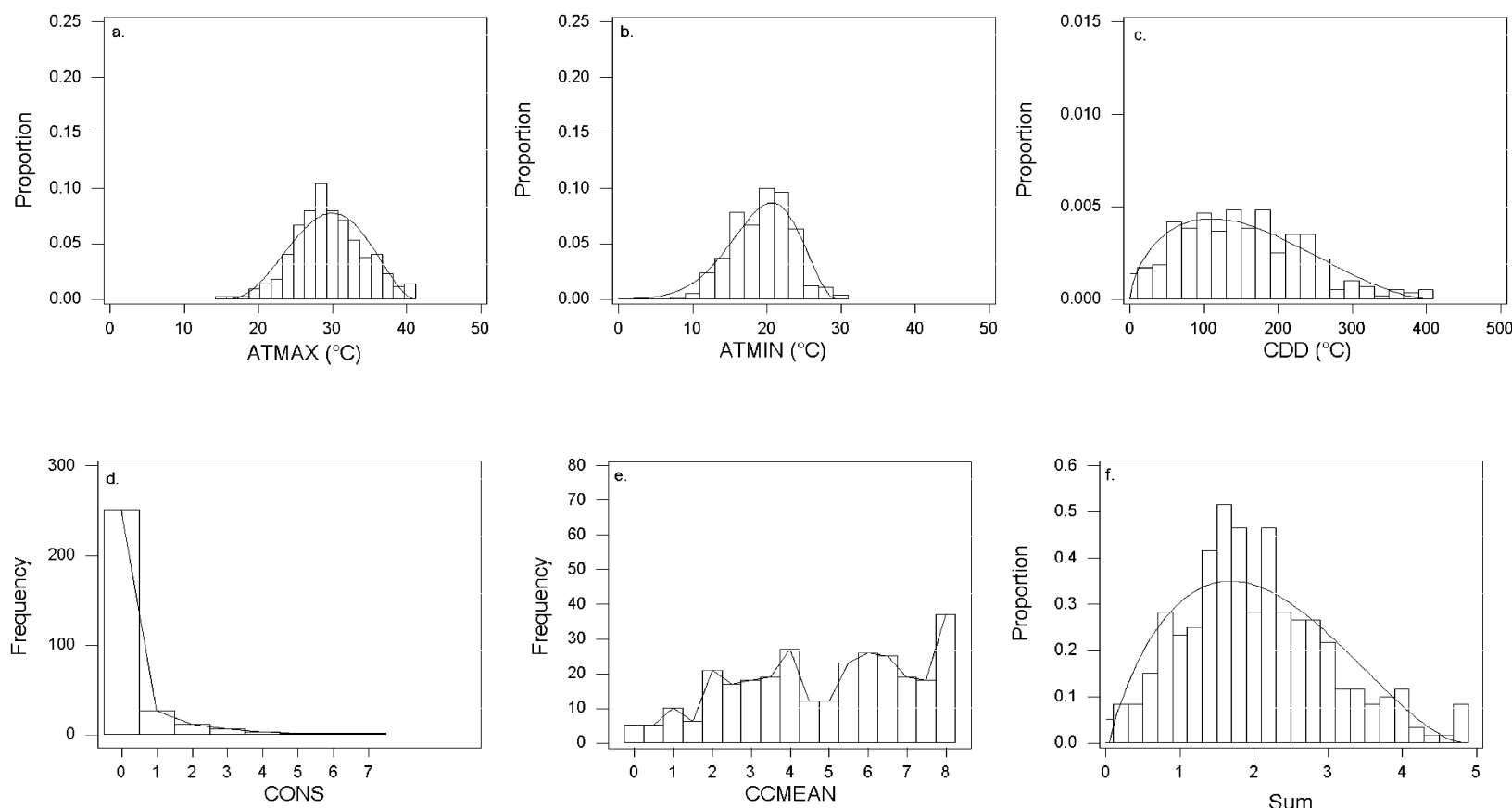

FIG. 3. Examples of (a) ATMAX, (b) ATMIN, (c) CDD, (d) CONS, (e) CCMEAN, and (f) summation (SUM) 1-10 Jul frequency distribution curves for Philadelphia.

of each variable for each observation using a cumulative distribution function (CDF). The cumulative probability of a negative binomial distribution is determined by summing the $p(x)$ values to the actual daily parameter for that given day. However, the CONS results had to be adjusted because the zero days were such an overwhelming majority at each location. The zero days were set equal to a probability of zero, $p(0)$, and the other consecutive-day cumulative probabilities, $p_{a}(x)$, were scaled as

$$
p_{a}(x)=\left[\frac{p(x)}{1-p(0)}\right]^{3}
$$

such that $p_{a}(x)$ represented the adjusted daily values for each CONS observation. The equation was cubed so that the CONS percentile values would be more intuitive. This adjustment enables the first day of consecutive heat stress to be lower than the 50th percentile and increases the percentile difference with increasing consecutive days.

Based on the definition of a CDF, a similar process was applied to the empirical fit of CCMEAN. The probability associated with a specific CCMEAN value was assumed to be equivalent to the frequency of its occurrence in relationship to the total number of CCMEAN observations over the $30-y r$ period. Thus, a cumulative sum of the probabilities up to and including the CCMEAN value for a given day represented the area under the empirical curve and became the CCMEAN's percentile value.

An example of the weather variables representing conditions on 4 July 1999 in Philadelphia and their corresponding daily percentile values based on their location under the curves is given in Table 1 .

The fifth step requires the summation of the daily percentile values for each of the five variables for each day and location. The summation is simply

$$
\begin{aligned}
\text { SUM }= & \text { ATMAX }+ \text { ATMIN }+ \text { CDD }+ \text { CONS } \\
& +(1-\text { CCMEAN }) .
\end{aligned}
$$

CCMEAN is subtracted from 1.0 to account for the fact that clear, rather than overcast, conditions add the most stress to a daytime situation. The summation value based on the Philadelphia example in Table 1 is equal to 3.95 .

Two issues were considered when addressing the relative weight of the variables in the summation algorithm. The first involved the explained variance associated with each variable in the index. Because of collinearity among the variables, it seemed more logical to weight them based on their uniqueness within the dataset. An attempt was made to use nonrotated principal components analysis (PCA), which is a multivariate statistical procedure designed to remove intercorrelation between variables, as described by Daultrey (1976). The results of the PCA were problematic and nonintuitive. There is no logical explanation of how the days are ranked, and principal components are notoriously difficult to interpret. Because of these problems, it was decided to apply equal weights to the variables; for more details on this issue refer to Derby (2002).

The second issue involving the weighting of variables relates to the impact of the parameters upon the envi- 

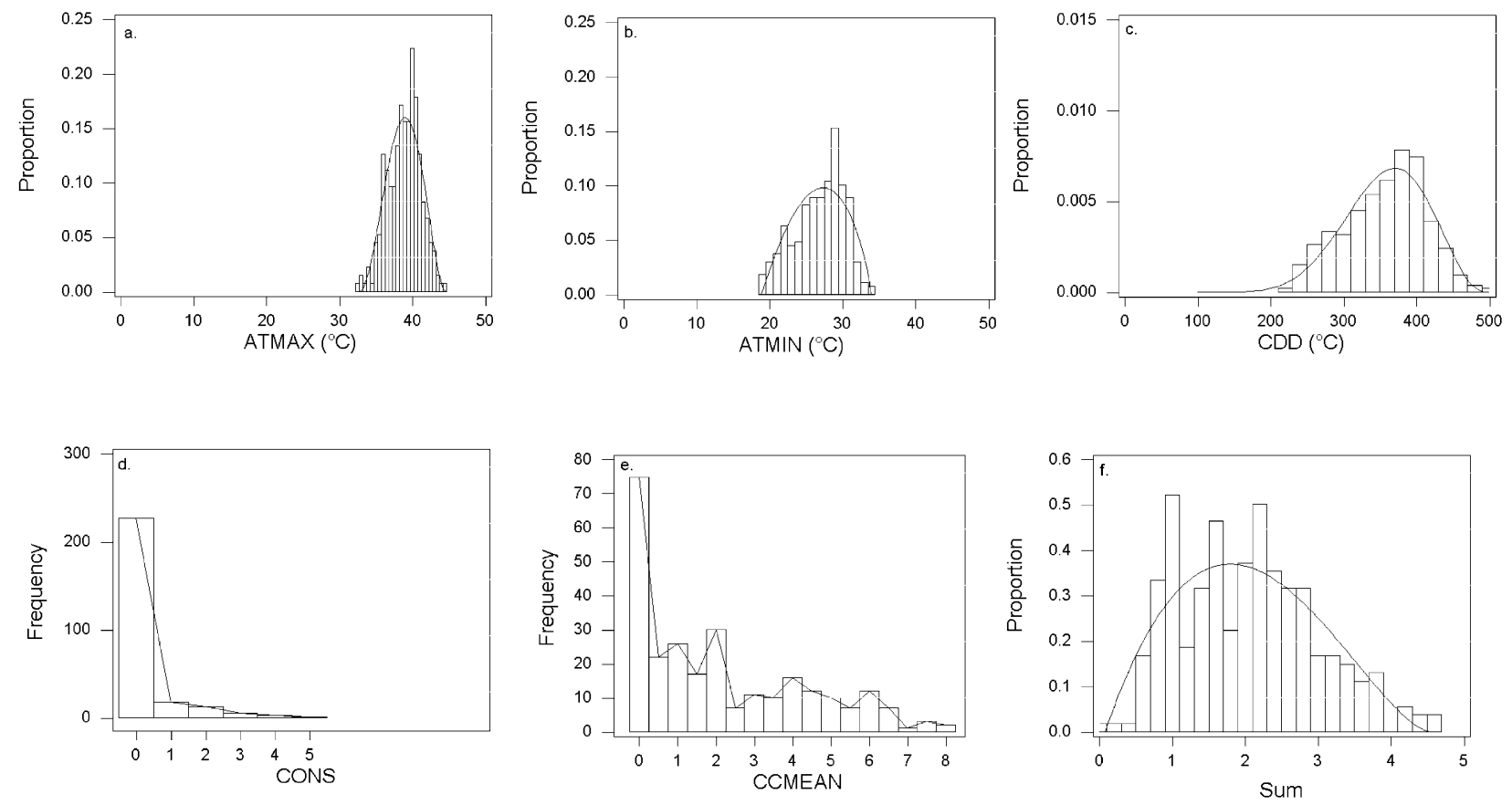

FIG. 4. Same as in Fig. 3 but for the 1-10 Jul frequency distribution curves for Phoenix.

ronmental application being evaluated. For example, minimum apparent temperature may be disproportionately important when affecting heat-related human mortality, whereas maximum apparent temperature may have unusually high significance when evaluating utility peak load. Because the HSI is designed as a "multiple use" index for a large variety of environmental and social factors, it is unwise to vary these weights for any single environmental application. A suggested procedure to overcome this issue of weighting is, first, to isolate the HSI days that are most stressful and second, within those days, to determine which variables most significantly affect the environmental factor being evaluated. This approach has been used successfully in the development of numerous heat/health watch/warning systems, in which oppressive air masses associated with high human mortality have been isolated, and the offensive variables within those air masses are then determined through correlation procedures and are used to develop predictive algorithms (Kalkstein et al. 1996).

The sixth step is to fit a distribution to the summed values by following guidelines similar to those given in the third step (Figs. 3f, 4f). The beta distribution func-

TABLE 1. Philadelphia weather variables and their corresponding daily percentile values for 4 Jul 1999.

\begin{tabular}{lcc}
\hline \hline Variable & Data & Daily value \\
\hline ATMAX & $39^{\circ} \mathrm{C}$ & 0.99 \\
ATMIN & $27^{\circ} \mathrm{C}$ & 0.97 \\
CDD & $354^{\circ} \mathrm{C}$ & 0.99 \\
CONS & 2 & 0.51 \\
CCMEAN & 5.11 & 0.51 \\
\hline
\end{tabular}

tion is chosen based on the overall summation frequency patterns for each 10-day period and location.

Last, the seventh step is the calculation of index values for every summer day within each station's 30-yr dataset based on the percentile of each summation (SUM) value (similar to the fourth step). For example, the values reported in Table 1 for 4 July 1999 in Philadelphia result in a $97 \%$ day.

\section{c. Forecasting capabilities}

The HSI can be forecast for time periods up to $48 \mathrm{~h}$ in advance. The input data currently come from the Aviation (AVN) run of the National Centers for Environmental Prediction Global Spectral Model (Dallavalle and Erickson 2000; Erickson et al. 2002). The AVN data are linearly interpolated to approximate weather parameters for the hours that occur within the 3-h intervals provided. Among the weather parameters forecast are temperature, dewpoint, cloud cover, and wind speed, which are all required to calculate the HSI. Each parameter needs to be converted to the appropriate units. Cloud cover is represented by character abbreviations rather than in numerical format, and so the abbreviations are defined numerically as CL (clear) $=0.0$, SC (scattered $)=2.0, \mathrm{BK}($ broken $)=6.0$, and OV $($ overcast $)=$ 8.0. The HSI is calculated for "today" and "tomorrow" using the 0000 UTC data but is updated to include today, tomorrow, and the following day when the 1200 UTC model data become available. With improving midrange forecasting from the National Oceanic and Atmospheric Administration (NOAA) Climate Prediction Center, it 
TABLE 2. Comparison of HSI values and components given the assumption that the same weather conditions applied at various locations.

\begin{tabular}{|c|c|c|c|c|c|c|c|}
\hline Variable & Data & Philadelphia & Phoenix & Baton Rouge & Miami & Cheyenne & Des Moines \\
\hline ATmax & $35^{\circ} \mathrm{C}$ & $86 \%$ & $5 \%$ & $47 \%$ & $69 \%$ & $100 \%$ & $85 \%$ \\
\hline ATmin & $23^{\circ} \mathrm{C}$ & $82 \%$ & $18 \%$ & $28 \%$ & $7 \%$ & $100 \%$ & $90 \%$ \\
\hline CDD & $261^{\circ} \mathrm{C}$ & $88 \%$ & $5 \%$ & $43 \%$ & $26 \%$ & $100 \%$ & $90 \%$ \\
\hline CCMEAN & 3.78 & $57 \%$ & $20 \%$ & $55 \%$ & $73 \%$ & $47 \%$ & $46 \%$ \\
\hline CONS & 1 & $20 \%$ & $25 \%$ & $25 \%$ & $19 \%$ & $17 \%$ & $18 \%$ \\
\hline SUM & & 3.33 & 0.73 & 1.98 & 1.94 & 3.64 & 3.29 \\
\hline Daily value & & $88 \%$ & $9 \%$ & $51 \%$ & $49 \%$ & $95 \%$ & $86 \%$ \\
\hline
\end{tabular}

will be possible to forecast the HSI for periods beyond $48 \mathrm{~h}$.

\section{Evaluation}

\section{a. Index analysis}

Heat stress index values were calculated for each summer day over the 30-yr period from 1971 to 2000 for each of the 230 first-order weather stations across the continental United States. The 30-yr period of record is archived for all of these stations, and the HSI is ready for general application. Spatial and monthly HSI comparisons were made for a number of stations, and the relative nature of the index is very apparent.

The weather conditions in Philadelphia on 3 July 1999 were evaluated to show what the HSI would be if those conditions occurred at other stations (Table 2). On 3 July 1999, Philadelphia, had partly cloudy skies and apparent temperatures high enough to consider this as a first consecutive day, which results in an $88 \%$ HSI value. Des Moines, Iowa, produced results very similar to those of Philadelphia; it is clear that there are similarities in summer climate between the two stations. However, the results for Baton Rouge, Louisiana, Phoenix, and Miami, Florida, assuming the same conditions, are very different. The 3 July 1999 Philadelphia ATMAX conditions are common occurrences in Baton Rouge and Miami at that time of year, and their ATMIN values at these southern locations rarely drop as low as Philadelphia's. Phoenix, Baton Rouge, and Miami would not begin a consecutive day count with ATMAX values that low, and so their overall index values are lower. The percentages associated with a partly cloudy sky are not highly variable among the locations, except

TABLE 3. Comparison of HSI values and components given the assumption that the same weather conditions applied to each warmseason month in Philadelphia.

\begin{tabular}{lcccccc}
\hline \hline Variable & Data & $\begin{array}{c}1-10 \\
\text { Jul }\end{array}$ & $\begin{array}{c}1-10 \\
\text { May }\end{array}$ & $\begin{array}{c}1-10 \\
\text { Jun }\end{array}$ & $\begin{array}{c}1-10 \\
\text { Aug }\end{array}$ & $\begin{array}{c}1-10 \\
\text { Sep }\end{array}$ \\
\hline ATMAX & $35^{\circ} \mathrm{C}$ & $86 \%$ & $100 \%$ & $100 \%$ & $86 \%$ & $96 \%$ \\
ATMIN & $23^{\circ} \mathrm{C}$ & $82 \%$ & $100 \%$ & $98 \%$ & $72 \%$ & $91 \%$ \\
CDD & $261^{\circ} \mathrm{C}$ & $88 \%$ & $100 \%$ & $99 \%$ & $86 \%$ & $97 \%$ \\
CCMEAN & 3.78 & $57 \%$ & $65 \%$ & $61 \%$ & $59 \%$ & $55 \%$ \\
CONS & 1 & $20 \%$ & $25 \%$ & $32 \%$ & $17 \%$ & $17 \%$ \\
SUM & & 3.33 & 3.90 & 3.90 & 3.20 & 3.56 \\
Daily value & & $88 \%$ & $96 \%$ & $95 \%$ & $86 \%$ & $91 \%$ \\
\hline
\end{tabular}

for Phoenix, where clear skies are so dominant that any cloudiness is associated with a low percentage. Based on this example, residents of Des Moines, Philadelphia, and Cheyenne, Wyoming, are experiencing moderate to severe heat stress and should be advised of potential health risks. People living in Baton Rouge and Miami deem these weather conditions to be somewhat typical; in Phoenix, these conditions would be unusually cool for a July day.

In an evaluation of relative stress on a temporal scale, the same 3 July 1999 weather conditions were also assumed to occur at Philadelphia at different times during the warm season: the first 10 days of May, June, August, and September (Table 3). In general, these conditions would be less frequent and therefore more stressful if they occur in any of these months. The individual variable percentages are higher in every category, especially during May and June. The August percentages also tend to be higher but are much closer to the July percentages. Very little variation is seen in cloud cover from one month to the next, except in the beginning of May.

Although the HSI results are relative to each location, if this index is robust, then there should also be considerable similarity among neighboring stations. An evaluation among adjacent stations shows a very high rate of correspondence, and the few exceptions can be logically explained. Philadelphia and Wilmington, Delaware, (51 km to the south of Philadelphia) represent a good example of station pairs for which variable distribution curves and day-to-day weather patterns are similar. Their HSI values have an overall correlation value of 0.95 .

Occasionally there are station pairs that produce very different HSI values. For example, Phoenix and Tucson, Arizona, are only $187 \mathrm{~km}$ apart but their variable frequency curves are not similar (Fig. 5). Tucson is cooler and somewhat cloudier than Phoenix. This result is clearly related to topography; Tucson's elevation of 777 $\mathrm{m}$ is more than 2 times that of Phoenix. These dissimilar variable curves are a major contributor to the 0.78 correlation found between Phoenix and Tucson's HSI values. When the weather conditions in Tucson are close to the average conditions in Phoenix, the index at Tucson returns extreme values. For example, on 12 August 1993, Tucson has an index value of $95.42 \%$, whereas Phoenix's HSI is only $53.30 \%$ even though the ATMIN 

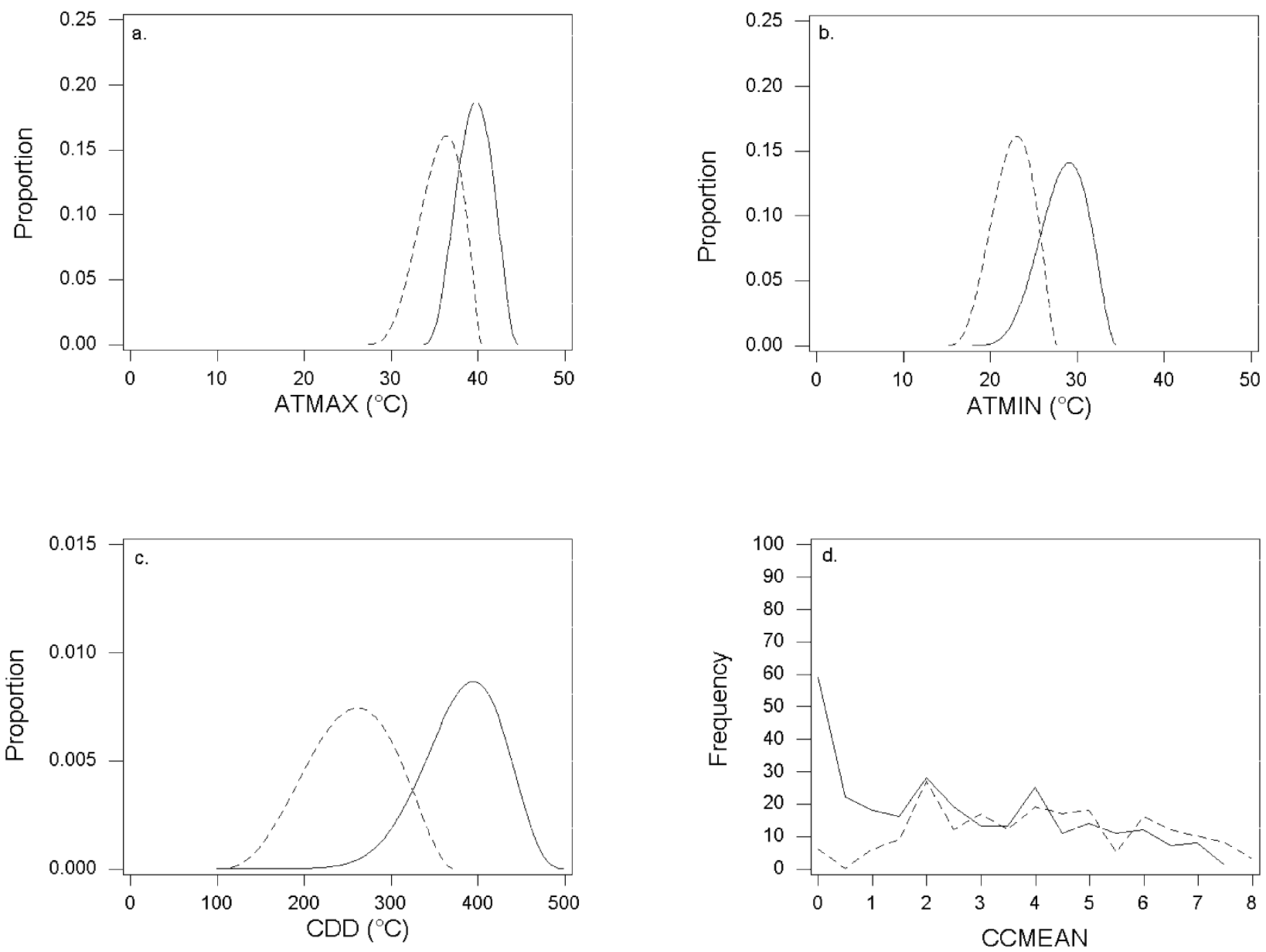

FIG. 5. Phoenix (solid line) and Tucson (dashed line) 1-10 Aug distribution comparisons provide an example of how the climate differs between the two locations.

at Phoenix remains higher (Table 4). Tucson's CONS baseline values are also much lower than those in Phoenix. During August, Tucson begins a CONS count when ATMAX is above $36.9^{\circ} \mathrm{C}$, but Phoenix does not begin until ATMAX reaches $41.0^{\circ} \mathrm{C}$.

The analysis of Phoenix and Tucson explains why it is important to calculate different HSI means, even at nearby stations. In essence, Tucson should not be compared with Phoenix because their curves are so different, based upon significant differences in geography, and, as

TABle 4. Comparison of HSI values for Phoenix and Tucson on 12 Aug 1993. The daily percentile values of each variable are provided in parentheses.

\begin{tabular}{lcccc}
\hline \hline & \multicolumn{2}{c}{ Phoenix } & \multicolumn{2}{c}{ Tucson } \\
\hline ATMIN $\left({ }^{\circ} \mathrm{C}\right)$ & 26.4 & $(0.40)$ & 23.4 & $(0.69)$ \\
ATMAX $\left({ }^{\circ} \mathrm{C}\right)$ & 38.4 & $(0.47)$ & 38.6 & $(0.94)$ \\
CDD $\left({ }^{\circ} \mathrm{C}\right)$ & 343.0 & $(0.42)$ & 316.4 & $(0.96)$ \\
CONS & 0 & $(0.00)$ & 4 & $(0.57)$ \\
CCMEAN & 0.00 & $(0.79)$ & \multicolumn{2}{c}{$2.78(0.52)$} \\
SUM & 2.08 & \multicolumn{2}{c}{3.68} \\
Daily $\%$ & 53.03 & \multicolumn{2}{c}{95.42} \\
\hline
\end{tabular}

a result, meteorological conditions. Thus, human and societal responses to meteorological conditions in these two cities are not as similar as one might expect, even though they are both in desert climates. This case is more common in the western United States, where varying topography over short distances can cause differential meteorological characteristics.

Explanations can also be offered about less common poor relationships that sometimes occur for station pairs whose curves are similar. The typical situation is that there is a weather phenomenon that affects one station, but not the other, such as a cold front progressing through the area that causes one station's HSI to be lower than the other's. Another major contributor to differing HSI values at nearby stations is when ATMAX is near the consecutive day baseline at each location. For example, on 21 July 1994, Philadelphia's HSI is $96.58 \%$ while the index in Wilmington is $75.57 \%$ (Table $5)$. The 21-31 July consecutive baseline value for Philadelphia is $34.2^{\circ} \mathrm{C}$ and the value at Wilmington is $33.5^{\circ} \mathrm{C}$. Philadelphia continues its CONS count on the third day while Wilmington resets to zero. The differ- 


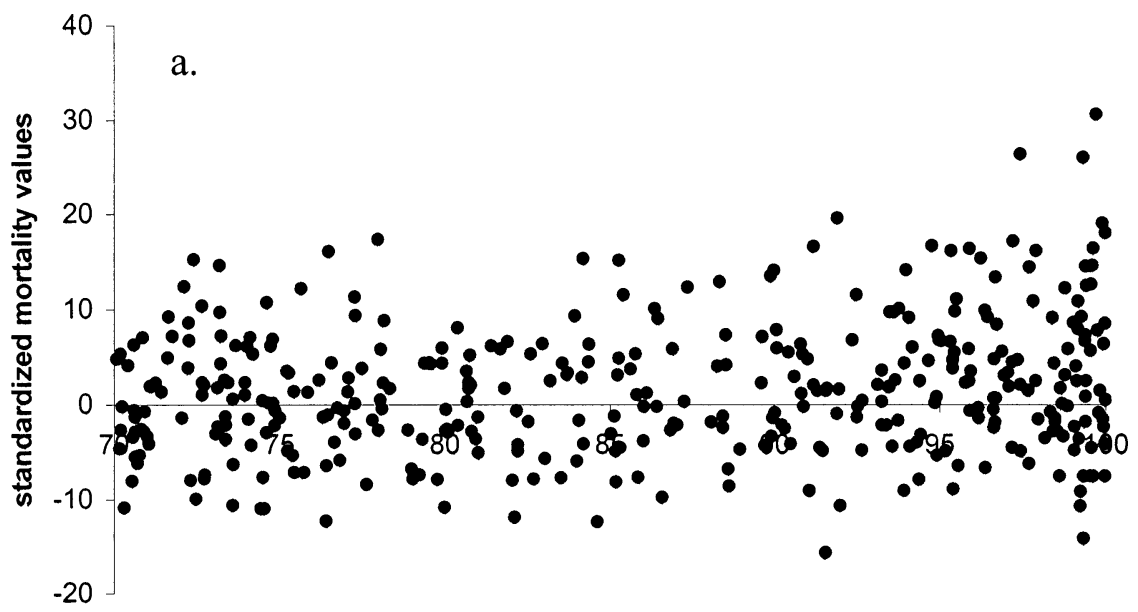

HSI values (\%)

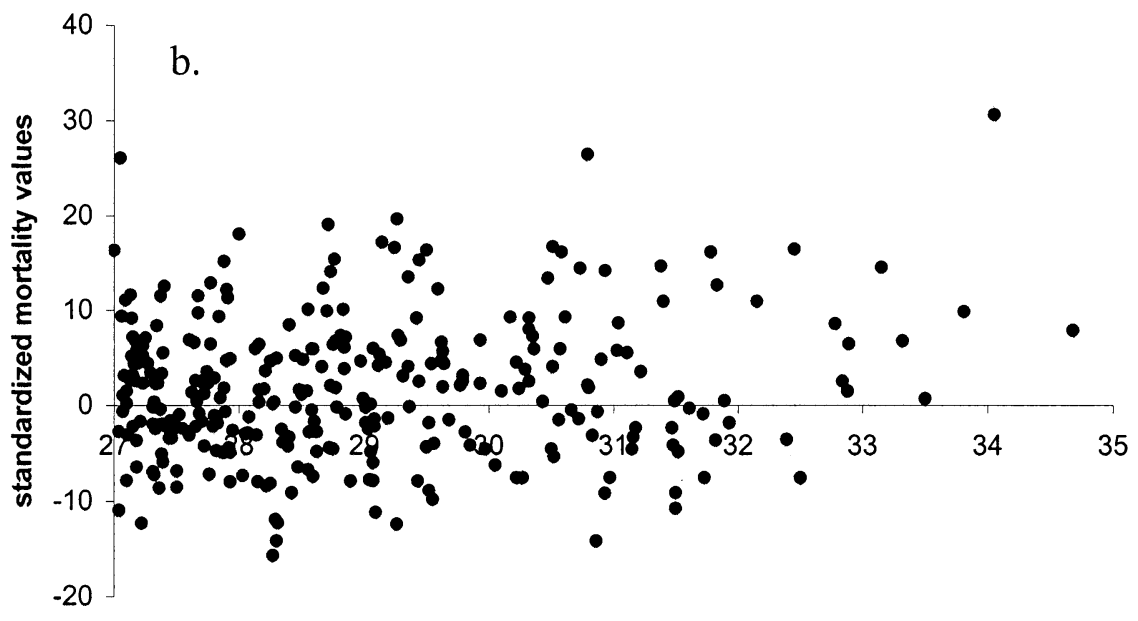

daily mean $\mathrm{AT}$ values $\left({ }^{\circ} \mathrm{C}\right)$

FIG. 6. (a) HSI values and (b) mean AT values vs mortality among the elderly for Philadelphia during the summers of 1975-92. The mortality data were standardized based on the 3-month interval (Jun, Jul, Aug) yearly means.

ence in the variable percentage of the three consecutive days versus a zero consecutive day is dramatic enough to cause such an index deviation from one location to the other. However, given the large number of similar

TABLE 5. Comparison of HSI values for Philadelphia and Wilmington on $21 \mathrm{Jul} 1994$. The daily percentile values of each variable are provided in parentheses.

\begin{tabular}{lcccc}
\hline \hline & \multicolumn{2}{c}{ Philadelphia } & \multicolumn{2}{c}{ Wilmington } \\
\hline ATMIN $\left({ }^{\circ} \mathrm{C}\right)$ & $27.0(0.97)$ & $25.7(0.95)$ \\
ATMAX $\left({ }^{\circ} \mathrm{C}\right)$ & 35.4 & $(0.87)$ & $33.0(0.74)$ \\
CDD $\left({ }^{\circ} \mathrm{C}\right)$ & $293.9(0.93)$ & $259.3(0.86)$ \\
CONS & 3 & $(0.57)$ & 0 & $(0.00)$ \\
CCMEAN & \multicolumn{2}{c}{$4.56(0.55)$} & \multicolumn{2}{c}{$5.78(0.30)$} \\
SUM & 3.88 & 2.86 \\
Daily \% & 96.58 & \multicolumn{2}{c}{75.57} \\
\hline
\end{tabular}

values between adjacent stations, occasions when proximate stations have HSI values that differ greatly are rare.

\section{b. Mortality application}

Mortality rates among the elderly (65 yr and older) were compared with the HSI values in Philadelphia to test the effectiveness of the index for applied climatological problems. Steadman's AT daily mean values were also compared with the mortality data to see which index is a better indicator of conditions associated with higher mortality. Previous studies show the need to consider total deaths in heat-mortality studies (Kalkstein 1991). Mortality data were obtained for each June, July, and August between 1975 and 1992 (National Center 

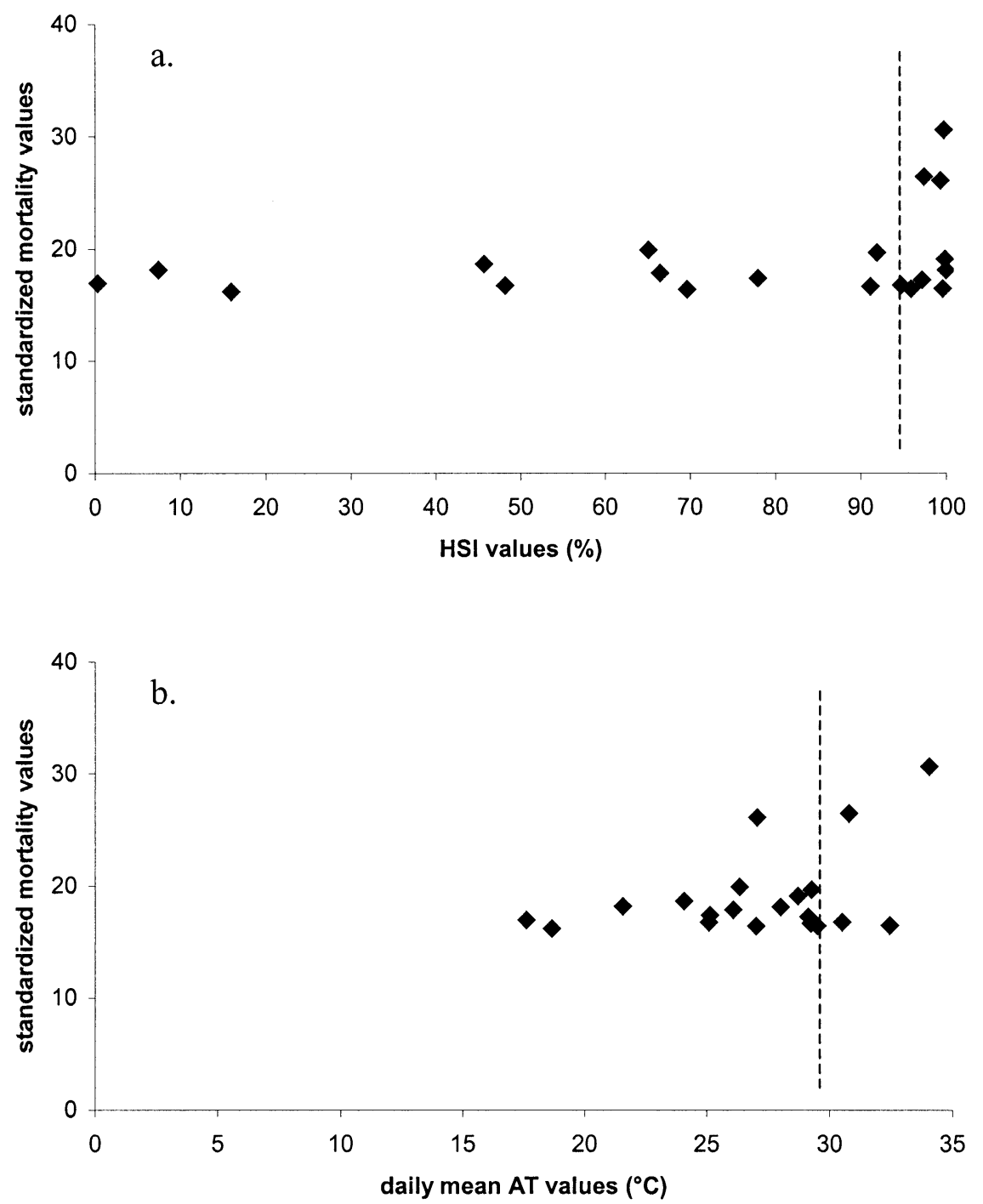

FIG. 7. Top 20 mortality days plotted against the (a) HSI values and (b) mean AT values during the summers of 1975-92. Dashed line separates the top 5\% HSI values and mean AT values. The mortality data were standardized based on the 3-month interval (Jun, Jul, Aug) yearly means.

for Health Statistics 2001). The data were standardized about the 3-month interval yearly mean to remove fluctuations and long-term trends.

As expected, there is an overall trend toward increasing mortality among the elderly once the HSI values are above $70 \%$ (Fig. 6a). The trend becomes more obvious once the HSI rises above 79\%. However, a similar pattern occurs when daily mean AT values are considered. Mortality among the elderly generally increases as mean AT rises above $27^{\circ} \mathrm{C}$ (Fig. 6b).

The HSI and mean AT values are difficult to compare because of differences in scale, but some important distinctions are apparent. Days with the highest mortality are grouped at the high end of the HSI scale, whereas they occur at a much wider range of AT values. This result suggests that for AT there are a number of days when above-average mortality occurs even when values are not so extreme.

An evaluation of the top 20 mortality days is instructive. Note that only 12 of the 20 are above the $70 \%$ HSI value and $27^{\circ} \mathrm{C}$ mean AT value, indicating that not all high-mortality days occur during periods of excessive heat stress (Figs. 7a,b). However, 8 of the top 12 results, including the three highest-mortality days, are associated with HSI values above $95 \%$, whereas only 4 of the top 12 occur within the top 5\% of AT values (for Philadelphia, defined to be greater than $29.9^{\circ} \mathrm{C}$ ). This suggests that the HSI does a better job than AT in isolating the highest-mortality days. The comprehensive nature of the HSI, as well as the relative component, renders it an improvement over the simpler and absolute AT values. 


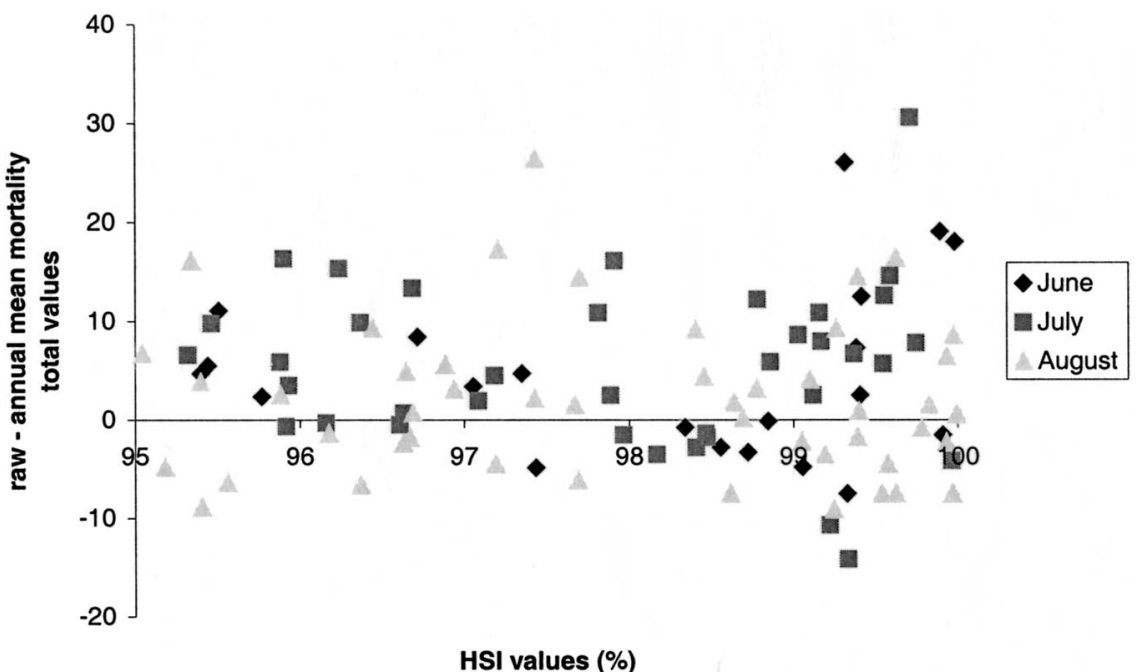

FIG. 8. Days with HSI values $95 \%$ and greater vs mortality among the elderly categorized by month.

One drawback of the HSI is that it cannot always be surmised that days close to $100 \%$ will signify aboveaverage mortality. To be specific, $34.8 \%$ of the days with index values of $95 \%$ and above are below average in mortality. Most of the highest HSI days with belowaverage deaths occur during August (Fig. 8), which suggests an acclimatization to heat occurs as the season progresses, causing fewer deaths by the end of the summer. Another possibility is that elderly, ill, and infirm people most susceptible to dying from heat stress die earlier in the summer. The fact that three out of the five highest-mortality days occur during June, coupled with the knowledge that June has the least number of belowaverage mortality days, supports this theory. If the HSI were ever to be implemented in mortality applications, an inclusion of a time-of-year variable would be essential to distinguish these intraseasonal differences.

\section{Conclusions}

The HSI is an improvement over other public-oriented indices, because it considers relative stress and adaptation based on spatial and temporal conditions. In addition, the relative index includes some parameters that have not been incorporated into other indices but are proven contributors to heat stress and numerous health and social problems. The index is based on maximum and minimum apparent temperature, cloud cover, cooling degree-days, and the number of consecutive days of extreme heat. These values are evaluated for locations throughout the United States based on deviations from average conditions during the months of May-September. A 97\% HSI value indicates that only $3 \%$ of days on that date are expected to experience more stressful conditions than the day under review.

As is the case with all climatic indices, the HSI represents an abstraction of reality and is not perfect. It would be appealing if the influence of the individual variables within the index could vary, but, if an index is to have a broad application, this characteristic is difficult to do. Upon developing the HSI, the following question was asked, "Is this index a significant improvement beyond what is most often used now by the NWS, by the public, and in general climate research?" We believe the intraseasonal and temporal relative nature of the index is a significant improvement. In addition, the inclusion of variables not found in commonly used indices is a second advantage of the HSI. It is also emphasized that if an index of this type is to have widespread applicability, it must depend upon easily obtained and commonly forecast variables. This consideration is surely key; all variables used in the HSI are easily extracted from all first-order weather stations and are available as forecasts from public or private entities.

The HSI could benefit both the operational and research fields with its ability to be used in numerous environmental applications. During the summers of 2001-02, HSI forecasts were disseminated as part of an experiment to determine the public's reaction to a relative index. The index was calculated $48 \mathrm{~h}$ in advance using the AVN forecasts. Based on discussions with the National Weather Service, HSI values were converted to a scale from 0.0 to 10.0 and descriptors were used to render the index simple for public consumption (e.g., HSI values between 9.0 and 9.5 were considered "severe," and between 9.6 and 10.0 they were labeled "extreme"). The overall results of a Web site-based poll were highly positive, with the vast majority of users saying that the index should continue. There is discussion about expanding the HSI to worldwide locations within temperate climates for all or part of the year and, possibly, creating a winter relative index. The HSI can also be incorporated within various health-oriented ini- 
tiatives such as heat/health watch/warning systems, for which it is necessary to determine threshold conditions that lead to declines in human health. The HSI may also be very useful in applications such as electricity and water demand associated with heat stress.

For some applications, it may be useful to implement an absolute meteorological determinant to add value to the HSI evaluation. For example, HSI values above $95 \%$ are not always associated with increased mortality. Therefore, a flexible threshold, based on geographic location and time of year, could be established if the HSI is used to issue heat watches and warnings. Because thresholds are unique to each application, they are best used as companions to the HSI rather than being incorporated into the HSI algorithm.

The HSI is a work in progress, and there are plans to continue to refine the index based on user needs, to increase forecasting accuracy, and to test overall effectiveness. However, the general concept of a relative index is sound, and it represents a required means in the way the impact of weather upon society is evaluated.

Acknowledgments. Thanks are given to NOAA's National Climatic Data Center (NCDC) for funding the initial work on this project and for their continued involvement in its development (Award 40-ELNE-100007). Thanks also are given to Mr. Mark Tew, NOAA/ Climate Prediction Center, for his ongoing support. Appreciation goes to WCAU-TV in Philadelphia, WAFBTV in Baton Rouge, and the NOAA/NWS for being involved in our public-response experiment.

\section{REFERENCES}

Balling, R. C., Jr., and S. W. Brazel, 1986: Temporal analysis of summertime weather stress levels in Phoenix, AZ. Theor. Appl. Climatol., 36, 331-342.

Dallavalle, J. P., and M. C. Erickson, 2000: AVN-based MOS guidance-The alphanumeric message. NWS Tech. Procedures Bull. 463, National Oceanic and Atmospheric Administration, 12 pp.

Daultrey, S., 1976: Principal components analysis. Concepts Tech. Mod. Geogr., 8, 1-51.

Derby, J. C., 2002: The development of a warm weather relative comfort index for environmental analysis. M.S. thesis, Dept. of Geography, University of Delaware, $129 \mathrm{pp}$.

Erickson, M. C., J. P. Dallavalle, and K. L. Carroll, 2002: The new AVN/MRF MOS development and model changes: A volatile mix? Preprints, 16th Conf. On Probability and Statistics in Atmospheric Sciences, Orlando, FL, Amer. Meteor. Soc., 82-87.

Hevener, O. F., 1959: All about humiture. Weatherwise, 12, 56, 8385

Höppe, P, 1999: The physiological equivalent temperature-A universal index for the biometeorological assessment of the thermal environment. Int. J. Biometeor., 43, 71-75.

Jendritzky, G., A. Maarouf, and H. Staiger, 2001: Looking for a universal thermal climate index (UTCI) for outdoor applications. Moving Thermal Comfort Standards into the 21st Century Conf., Windsor, United Kindom, OCSD, 353-367.

Kalkstein, L. S., 1991: A new approach to evaluate the impact of climate on human mortality. Environ. Health. Perspect., 96, 145150 .

, and K. M. Valimont, 1986: An evaluation of summer discomfort in the United States using a relative climatological index. Bull. Amer. Meteor. Soc., 67, 842-848.

- , and - 1987: An evaluation of winter weather severity in the United States using the weather stress index. Bull. Amer. Meteor. Soc., 68, 1535-1540.

__ , and R. E. Davis, 1989: Weather and human mortality: An evaluation of demographic and interregional responses in the United States. Ann. Assoc. Amer. Geogr., 79, 44-64.

_, P. F. Jamison, J. S. Greene, J. Libby, and L. Robinson, 1996: The Philadelphia Hot Weather-Health Watch/Warming System: Development and application, summer 1995. Bull. Amer. Meteor. Soc., 77, 1519-1528.

Karl, T. R., and R. W. Knight, 1997: The 1995 Chicago heat wave: How likely is a recurrence? Bull. Amer. Meteor. Soc., 78, 1107 1119.

Kilbourne, E. M., 1997: Heat waves and hot environments. The Public Health Consequences of Disasters. Oxford University Press, 245-269.

Masterton, J. M., and F. A. Richardson, 1979: Humidex, a method of quantifying human discomfort due to excessive heat and humidity, CLI, 1-79, Environment Canada, 45 pp.

National Center for Health Statistics, cited 2001: Multiple cause-ofdeath mortality data for Philadelphia, PA. U.S. Department of Health and Human Services, Center for Disease Control and Prevention Rep., Hyattsville, MD. [Available online at http:// www.cdc.gov/nchs/products/elec_prods/subject/mortmcd.htm.]

National Climatic Data Center, cited 2003: Data documentation for data set 3280 (DSI-3280) surface airways hourly. [Available online at http://www4.ncdc.noaa.gov/ol/documentlibrary/datasets. html\#TD3280.]

NWS, 1992: Non-precipitation weather hazards (C-44). WSOM Issuance 92-6, 5-7.

Steadman, R. G., 1979a: The assessment of sultriness. Part I: A temperature-humidity index based on human physiology and clothing science. J. Appl. Meteor., 18, 861-873.

_, $1979 \mathrm{~b}$ : The assessment of sultriness. Part II: Effects of wind, extra radiation and barometric pressure on apparent temperature. J. Appl. Meteor., 18, 874-885.

_- 1984: A universal scale of apparent temperature. J. Climate Appl. Meteor., 23, 1674-1687.

Thom, E. C., 1959: The discomfort index. Weatherwise, 12, 57-60. 